\title{
Entrepreneurship Potentials and its Role for Youth Livelihood Development
}

\author{
Article by Molla Mekonnen Alemu \\ PhD, Texila American University, Ethiopia \\ Email: mollamekonnen@gmail.com
}

\begin{abstract}
The potentials of entrepreneurship for unlocking youth-led livelihood development was explored in 5 districts of Sierra Leone, West Africa. Interviews, questionnaires, focus group discussion, and field observation were used to collect data. Reports and different literatures were also reviewed. The analyses of the survey indicated that entrepreneurship has a great potential in creating employment opportunities for young women and men. Poor microfinance services, inadequate policies and strategies along with low level of enforcement and poor infrastructure account as the major problem contributors to the low levels of entrepreneurship employment opportunities for the youth in Sierra Leone. The study also revealed as entrepreneurship development has a great alternative potentials which could help to reduce the present youth unemployment rate in the country. Offering credit facilities, business management skills, mentorship and coaching services to young enterprise operators and creation of the enabling environment (reinforcing of policies and strategies) for entrepreneurship are identified as the major contributors for entrepreneurship related employment opportunities.
\end{abstract}

Keywords: Entrepreneurship, youth, employment opportunities

\section{Introduction}

The uneven economic recovery and successive downward revisions in economic growth projections have had an impact on the global employment situation. Almost 202 million people were unemployed in 2013 around the world, an increase of almost 5 million compared with the year before. This reflects the fact that employment is not expanding adequately fast to keep up with the growing labor force (ILO, 2014).

Sierra Leone is still emerging from a period of post-conflict reconstruction which followed a decade of civil war, which ended in 2001. Central to the conflict lay a large group of marginalized young people, particularly from rural areas, who are mostly illiterate and without access to livelihood opportunities. Besides the challenges associated with the recovery for development phase, on the employment creation front, the limited capacity of the private sector and a generally difficult economic environment, exacerbated by the global economic crisis and its repercussions on the country's economy and labour market, have worsened the youth unemployment situation in the country.

The Sierra Leone National Youth Policy and the Youth Commission Act 2009 define youth as all Sierra Leonean female and male between the ages of 15 and 35 and it account for 34 percent of the population of Sierra Leone (GoSL, 2003). The civil war that ended in 2002 disrupted the availability and quality of educational services, exposed many youth to violence from a very young age, and created disincentives for young people to remain in school. As a result, members of this generation have less employable skills and opportunities, are less prepared for the job market and face a more difficult transition to adulthood than either younger or older groups. They constitute a vital component of the country's human resource capacity, capable of exerting profound impact on the socio-economic, political and security needs of the country (NAYCOM, 2012; NAYCOM, 2013).

Overall, employment is a structural issue and there are no quick off-the-shelf solutions that are sustainable and that will reach the majority of the youth which is considered to be 
underemployed or unemployed. Employment requires long-term equitable growth across sectors and regions. There are good practices that have been shown to be successful and that can be expanded. Additionally, many more opportunities can be made of existing opportunities if there are better linkages between sectors and initiatives; a much more supportive policy environment and targeted interventions based on detailed assessments (NAYCOM, 2012b).

The private sector in Sierra Leone, as in most African countries, has remained largely informal. Less than $15 \%$ of private sector employment can be linked to the formal sector. The private sector has the potential to substantially increase productive and adequately remunerative employment in response to market opportunities and business innovation, if sufficient attention is paid to the development of micro and small and medium enterprises (SMEs). Employment promotion should therefore emphasise the provision of an enabling policy and strategy environment and a favourable business climate for private sector development, including in particular skills development and entrepreneurship training and the availability of a start-up capital. This should be seen as an instrument to achieve employment creation and other desired development outcomes in the country (MLSS and MYES, 2011; GoSL, 2008).

\section{Objectives}

The main objectives of the study are i) to highlight the major bottle necks of youth led entrepreneurship development opportunities; ii) to analyze the potential benefits of entrepreneurship development for youth led employment opportunities; and iii) based on the findings of the study, to propose different scenarios that can be used to promote youth entrepreneurship and livelihood development.

\section{Methodology}

The major activities of the study were started by conducting a preliminary reconnaissance survey. Then the study was carried out by making use of the qualitative research technique. The participants (business operators) were selected by systematic sampling from five districts (Bo, Makenie, Kenema, Newton and Freetown) whereas the government officials and other development practitioner were selected by purposive sampling. Report reviews, semistructured questionnaire and interviews were used to gather the primary and secondary information. Focus group discussion was also held with young business operators. The research also undertook a comprehensive search for available literature, including policy, strategy and action plan documents. A total of 16 professionals and 62 business operators have participated in the data collection process.

Based on the type of methods used to collect the data, the information was analyzed through qualitative research analysis methods. The primary information collected through interview, observation and questionnaires was separately transcribed which helped the raw data to be ready for scientific analysis. Then content analysis of the information was made and main points were analyzed (Roulston, 2001; Boeije, 2010; Flick et al., 2004).

\section{Results and discussion}

Economic growth should lead to shared prosperity and should be measured not just by the rate of growth but also by the degree to which growth improves the well-being of people on an equitable and sustainable manner. This type of inclusive growth is founded on the creation of decent jobs, improvement in livelihoods and rising real incomes for all (ECOSOC, 2015).

Small and medium-sized enterprises (including smallholder farmers and agri-businesses) deliver essential goods and services to their communities at different levels. Effective entrepreneurial development can set in motion a wave of impacts in communities and regions that go beyond the wealth created by individual entrepreneurs and their enterprises. Successful entrepreneurs create returns for their investors, often family and friends located in their regions. The growth of entrepreneurs often creates wealth that is rooted in the local 
region. Successful entrepreneurs may become donors to local community foundations and contribute their time, talent and treasure to other community endeavors (Deborah and Sarah, 2012).

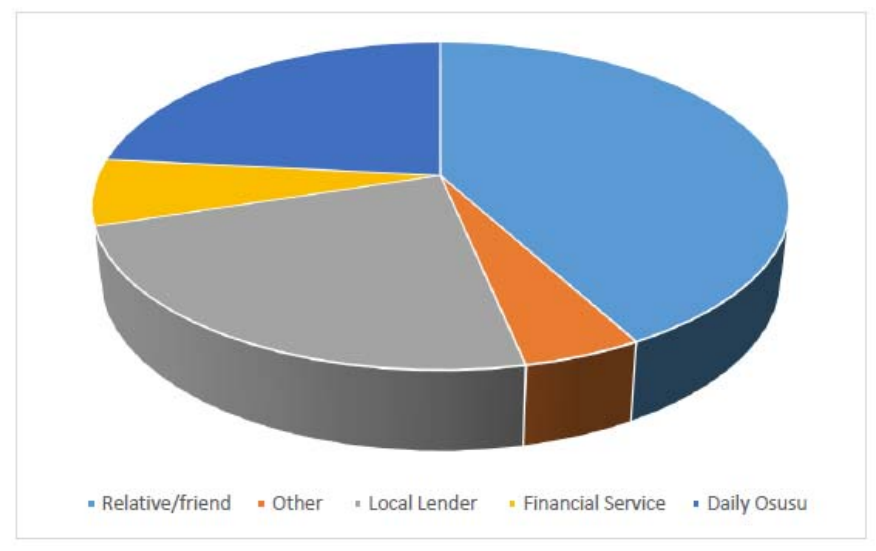

Fig. 1: Respondents analysis on the proportion of loan sources for entrepreneurship *Osusus: informal savings on a daily basis and will receive a cash pay-out one day a month (or per cycle among the group).

The main objective of informal entrepreneurs in production of goods and services is to generate income and employment opportunities that are centered on the individual. These units have low level organization patterns on a small scale. They are carried out on a small scale with labour and capital as well as limited division of labour among family members. The relations between the workers are temporary. Job opportunities depend on kinship relations and personal and social relations. The ownership of the units is not held by any other person than the informal entrepreneur. They do not have the ability to differentiate between production cost and household expenditure (Zuin, 2004: 12 cited in Pradeep et al., 2013).

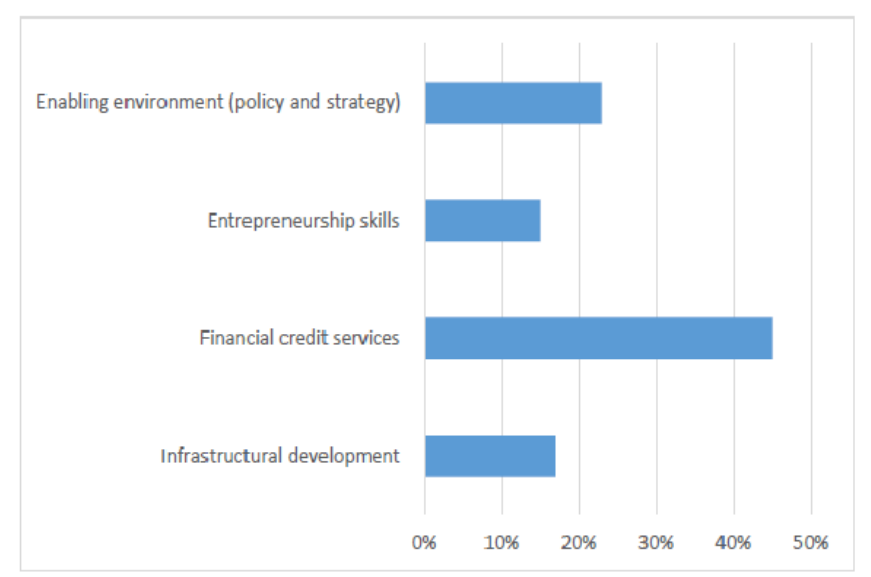

Fig. 2: Analysis of the problems affecting entrepreneurship.

The study explored that, the private sector in Sierra Leone, as in most African countries, has remained largely informal. Less than $15 \%$ of private sector employment can be linked to the formal sector (MLSS and MYES, 2011). Entrepreneurship development has a great potential to scale up the creation of employment generation for youth. Entrepreneurship development however, in Sierra Leone is still struggling from weak infrastructural development, weak financial credit services, and inadequate entrepreneurship management skills from the side of business operators as well as weak institutional arrangements to create enabling environment for the sector, these all exacerbating the unemployment rate especially among the youth. 
South American Journal of Management

Special Edition 2016

Entrepreneurship development and promotion requires the very existence and placement of several development factors. Amongst, however the creation of an enabling environment in terms of policy, strategy and institutional framework arrangements will play a paramount role in ensuring the role of entrepreneurship for creating livelihood opportunities for the youth. Business skills development which can enable young business operators to manage their businesses in the areas of business plan preparation, savings management, business expansion, records keeping, etc. will also play a significant role in the entrepreneurship development. Strengthening of local economic development by incorporating labour-intensive technologies and opportunities through public works at district and chiefdom levels by targeting youth and women can also lead to the creation of enterprises.

Private sector development is also very crucial for economic diversification and in transforming the growth path of the economy towards significant employment creation and poverty reduction benefits. The emphasis on private sector development goes beyond the large investors to include small and medium enterprises which have the greatest potential for job creation in the private sector. Strengthening the micro finance system in terms of credit scheme services for accessing start-up capital and existing business enterprises expansion backed well-targeted skills development programmes will also play a significant role for the development of the sector.

\section{Conclusion}

Entrepreneurship development has a great potential on economic as well as livelihoods development. Employment promotion through entrepreneurship development should therefore focus basically on the creation of an enabling environment in terms of policy, strategy and institutional arrangements. Provision of a favourable business climate for the private sector development, in particular skills development and entrepreneurship training and start-up capital will also play a key role for the livelihoods development of the youth. The expansion of business development services which can provide coaching and mentorship services to business operators will also boost enterprises development and serve as an instrument to achieve employment creation and other desired development outcomes for youth.

\section{References}

[1.] Boeije Hennie, 2010: Analysis in qualitative research (1st ed.). Los Angeles: SAGE.

[2.] Deborah M. Markley and Sarah A. Low, 2012: Wealth, Entrepreneurship, and Rural Livelihoods. Choices and the Agricultural \& Applied Economics Association. JEL Classifications: R1, O2, L26

[3.] ECOSOC (Economic and Social Council of the UN), 2015: High-level political forum on sustainable development convened under the auspices of the Council. High-level segment of the 2015 session of the Economic and Social Council.

[4.] Flick, U., Kardorff, E., and Steinke, I., 2004: A companion to qualitative research (1st ed.). London: Sage Publications.

[5.] GoSL (Government of Sierra Leone), 2008: Youth Agenda for Development. National Youth Commission, National Stadium Swimming Pool, Brookfields, Freetown.

[6.] GoSL (Government of Sierra Leone), 2003: Sierra Leone National Youth Policy, Freetown, Sierra Leone.

[7.] ILO, 2014: Global employment trends 2014: Risk of a jobless recovery? International Labour Office. Geneva.

[8.] MLSS and MYES (Ministry of Labour and Social Security and Ministry of Youth Employment and Sports (MYES), 2011: National Employment Policy: Combining Employment Creation with Economic Growth, Structural Transformation and Social Development. Freetown, Sierra Leone.

[9.] National Youth Commission (NAYCOM), 2012: Sierra Leone Status of Youth Report, Sierra Leone, Freetown. 
[10.] National Youth Commission (NAYCOM), 2012b: Partnerships for job creation for young people in countries emerging from conflict. Joint Event of ECOSOC and the Peacebuilding Commission. ECOSOC Chamber, NLB.

[11.] National Youth Commission (NAYCOM), 2013: Sierra Leone Status of Youth Report, Sierra Leone, Freetown.

[12.] Pradeep Uluwaduge et al., 2013: The Role of Informal Women Entrepreneurs in Livelihood Development and Regional Development. University of Sri Lanka, Sri Lanka

[13.] Roulston Kathryn, 2001: Data analysis and 'theorizing as ideology'. London Thousand Oaks, CA and New Delhi). 1(3): 279-302 